\title{
Staging the HCR-20: towards successful implementation of team-based structured professional judgement schemes
}

\author{
Quazi Haque \& Christopher D. Webster
}

\begin{abstract}
SUMMARY
Structured professional judgement risk management schemes such as the Historical, Clinical, Risk Management - 20 (HCR-20) can be described as clinical guidelines produced by a collaborative process between mental health clinicians and researchers. The purpose is to provide clinicians with a framework to guide interventions designed to manage specific risks such as violence against others. The use of evidence-based clinical methods, especially in a multidisciplinary setting, is now commonly considered a best-practice approach when managing violence and related risks. This article describes some of the practical implementation challenges that may arise when using schemes such as the HCR-20 in multidisciplinary team meetings.
\end{abstract}

\section{DECLARATION OF INTEREST}

C.D.W. is a co-author of version 2 of the HRC-20. O.H. and C.D.W. are training consultants on the use of this instrument.

There is an increasing clamour for the task of clinical risk assessment and management in mental health services to be shared through multidisciplinary team decision-making (e.g. Maden 2007, pp. 68-9; Douglas 2010, pp. 14785). Such an approach relies on professionals from different disciplines being able to amalgamate individual opinions into consensus judgements, often through team meetings. Multidisciplinary consensus approaches are considered to reduce the effect of bias from individual assessors and provide a framework for integrated risk management approaches (see Webster 2007: pp. 145-148). This type of approach is stressed as a key recommendation in the Department of Health (2007) document Best Practice in Managing Risk (Box 1).

Recent surveys indicate the increasing use of structured professional judgement approaches to managing violence and related risks in UK forensic mental health services (Khiroya 2009). Schemes such as the Historical, Clinical, Risk Management - 20 (HCR-20; Webster 1997) (Table 1) are now commonly used as clinical guidelines to help organise multidisciplinary risk assessment and management. Like most structured professional judgement measures, the HCR-20 attempts to retain the strengths of clinical decision-making, such as the focus on an individual's characteristics, while placing an emphasis on a certain amount of structure to the task in order to foster reliability, validity and transparency. Structure is found on the HCR-20 by the:

- inclusion of a fixed set of historical and current risk factors and future clinical 'dynamic' risk factors identified from the scientific and professional literature;

- operational definitions of risk factors;

- scoring or coding procedures for risk factors;

- direction for how to reach a final decision about risk based on the consideration of the risk factors present and relevant in each case.

The HCR-20 includes dynamic risk factors in order to facilitate the development of risk management plans. Furthermore, risk factors in the HCR-20 (particularly the C and R items) should be re-evaluated, and management plans should be developed to mitigate them. Re-evaluation of treatment, supervision and management strategies should typically take place when the person concerned has engaged in recent violence, has undergone notable recent changes in their presentation or circumstances, or a transition in professional care is being considered or will occur.

The strong support for an evidence-based multidisciplinary approach to clinical risk management, however laudable, is not easy to achieve. Clinicians are faced with the task of synthesising new knowledge with existing knowledge, beliefs and attitudes, while often
Quazi Haque is the Group Medical Director at Partnerships in Care and an honorary lecturer at the Institute of Psychiatry, London. His clinical and research interests include the development and evaluation of structured clinical risk assessment and management instruments within mental health and criminal justice settings. Christopher D. Webster is Professor Emeritus of Psychiatry, University of Toronto, and Professor Emeritus of Psychology, Simon Fraser University, Canada. He is a research and training consultant who specialises in the area of structured professional judgement approaches to violence assessment and management. Correspondence Dr Quazi Haque, Partnerships in Care, 2 Imperial Place, Maxwell Road, Borehamwood, Hertfordshire, WD6 1JN, UK. Email: Quazi.Haque@ partnershipsincare.co.uk 
BOX 1 Summary of 16 best practice points for effective risk management

1 Best practice involves making decisions based on knowledge of the research evidence, knowledge of the individual service user and their social context, knowledge of the service user's own experience, and clinical judgement.

2 Positive risk management as part of a carefully constructed plan is a required competence for all mental health practitioners.

3 Risk management should be conducted in a spirit of collaboration and based on a relationship between the service user and their carers that is as trusting as possible.

4 Risk management must be built on a recognition of the service user's strengths and should emphasise recovery.

5 Risk management requires an organisational strategy as well as efforts by the individual practitioner.

6 Risk management involves developing flexible strategies aimed at preventing any negative event from occurring or, if this is not possible, minimising the harm caused.
7 Risk management should take into account that risk can both be general and specific, and that good management can reduce and prevent harm.

8 Knowledge and understanding of mental health legislation is an important component of risk management.

9 The risk management plan should include a summary of all risks identified, formulations of the situations in which identified risks may occur, and actions to be taken by practitioners and the service user in response to crisis.

10 Where suitable tools are available, risk management should be based on assessment using the structured clinical judgement approach.

11 Risk assessment is integral to deciding on the most appropriate level of risk management and the right kind of intervention for a service user.

12 All staff involved in risk management must be capable of demonstrating sensitivity and competence in relation to diversity in race, faith, age, gender, disability and sexual orientation.

13 Risk management must always be based on awareness of the capacity for the service user's risk level to change over time, and a recognition that each service user requires a consistent and individualised approach.

14 Risk management plans should be developed by multidisciplinary and multi-agency teams operating in an open, democratic and transparent culture that embraces reflective practice.

15 All staff involved in risk management should receive relevant training, which should be updated at least every three years.

16 A risk management plan is only as good as the time and effort put into communicating its findings to others.

(Department of Health 2007: pp. 5-6) providing leadership to a team. Team members will bring particular experiences and expertise to bear, yet it can take some effort to keep inherent professional differences balanced (Webster 2007). Mental health practitioners across various disciplines need to be attentive to their own personal and professional viewpoints while being aware of new ideas and outlooks. The structured professional judgement approach of organising

\section{TABLE 1 The 20 items of the HCR-20}

\begin{tabular}{|lll|}
\hline $\begin{array}{l}\text { Historical } \\
\text { (past) }\end{array}$ & $\begin{array}{l}\text { Clinical } \\
\text { (present) }\end{array}$ & $\begin{array}{l}\text { Risk management } \\
\text { (future) }\end{array}$ \\
\hline H1. Previous violence & C1. Lacks insight & R1. Plans lack feasibility \\
\hline $\begin{array}{l}\text { H2. Young age at first violent } \\
\text { incident }\end{array}$ & C2. Negative attitudes & $\begin{array}{l}\text { R2. Exposure to } \\
\text { destabilisers }\end{array}$ \\
\hline H3. Relationship instability & $\begin{array}{l}\text { C3. Active symptoms of major } \\
\text { mental illness }\end{array}$ & $\begin{array}{l}\text { R3. Lack of personal } \\
\text { support }\end{array}$ \\
\hline H4. Employment problems & C4. Impulsivity & $\begin{array}{l}\text { R4. Non-compliance with } \\
\text { remediation attempts }\end{array}$ \\
\hline H5. Substance use & C5. Unresponsive to treatment & \begin{tabular}{l} 
R5. Stress \\
\hline H6. Major mental illness
\end{tabular} \\
\hline H7. Psychopathy & & \\
\hline H8. Early maladjustment & & \\
\hline H9. Personality disorder & & \\
\hline H10. Prior supervision failure & & \\
\hline
\end{tabular}

Note: The authors specifically warn against using these terms without full consideration of the item and other definitions in the manual.

(Source: Webster et al 1997). risk factors by way of a manual, rather than a checklist, provides an opportunity for these different perspectives to be considered but does not provide a sure-fire bypass around the need to maintain professional knowledge in the subject or to disregard unhealthy team dynamics.

We have chosen a narrative format to highlight some of the professional issues encountered by clinical teams when, for example, using a consensusbased approach to the application of the HCR-20. Inspiration for the current form of presentation is derived in part from Stephen Pfohl's Predicting Dangerousness (Pfohl 1979). This text revolves around a host of direct quotations from specially constituted interdisciplinary teams charged with completing court-ordered risk assessments on a large number of patients. The transcript reads like a play. Indeed, we sometimes invite participants in workshops to come to the front of the room and take the parts of psychiatrist, psychologist, social worker and patient, depending on the situation. Although it may be true that these transcripts contain statements and questions that fall far below professional standards, and were selected by Pfohl for precisely that reason, there are few better, and perhaps more chilling, ways of demonstrating the power of out-of-control team dynamics (e.g. individual members vying against one another to display seeming expertise; talking in front of the patient as if they were not in the room). 
The characters described are fictitious, but the discussions within this piece are, from our experiences, real and recurrent (e.g. Webster 2002).

\section{Setting}

The action takes places in an exceptionally seedy conference room. Lighting is dim. Coffee-stained mugs litter the table. Back issues of Hello magazine are scattered on the adjacent worn out sofa. There is a pervasive atmosphere of ennui - no one caring very much about anything. The DSM-IV and the ICD-10 lie on top of the bent, unlocked filing cabinet. A spirit of preservation has decreed that they not be sullied - both are wrapped in their original plastic sheathings.

\section{Cast of characters}

\section{Person A}

It is said that she graduated top of her class, but there is no confirmation of this. No knowledge exists of the class of which she was purportedly top. Like Bishop Wilberforce, as in the great debate with Charles Darwin, she has succeeded in life by accomplishing ever easier tasks. Now as a senior mental health professional, feared by all, she is making her 'last stand' (expected to take at least 5 years). She has seen the movie Doubt three times.

\section{Person B}

Too keen by far, no good will come of him. He is too committed to ensuring his patients get a fair shake and believes that all will work out for the best in the end. He still enjoys reading the Harry Potter series.

\section{Person C}

She is earnest to her core. Our hearts go out to her. According to gossip, she is independently wealthy. No one can understand why she works here.

\section{Person D}

He has just joined the unit. He wonders if he is up to the challenge. At present he is mainly concerned with fending off the advances of the new social worker (who could, it is generally thought, benefit from the purchase of some less revealing clothing).

\section{Case conference: $11.00 \mathrm{~h}$}

A I just saw Mr Lucas and, of course, I read the clinical file. I think you have all seen him and looked over the record? This is a pretty serious offence: attempted murder, death threats, etc. Lucky his father wasn't killed. From what I can figure, he could be bipolar with, possibly, some features of personality disorder. There's some paranoia floating about here as well.

I recently came across a systematic way of assessing violence risk. It's called Historical, Clinical, Risk Management - 20 (HCR-20). There are 20 items: 10 historical, 5 current clinical, and 5 risk items directed to the future. It scores as: 0, meaning it isn't there, 1 , meaning it may be present, and 2 , it is present. Total score is out of 40 , although assessors are expected at the end to give an overall rating of low, moderate or high risk. There is a manual which I have [Holds up manual]. But you don't really have to read it. The one page checklist is at the back and I've photocopied this for you [Hands round]. Any of you ever heard of this thing?

B Yes, I attended a workshop on it last year. The trainer mentioned that for clinical purposes the scores of 2, 1 and 0 could be replaced by coding each item as 'yes', 'maybe' and 'no' respectively.

C I was there too.

D I haven't been to a workshop, but I ordered a copy of the manual some time ago and have read it from cover to cover.

A Well, that's great. We're on the same page. My idea is that we should try the thing out on the case of Mr Lucas. I guess it could speed things up. Maybe we could get this done in 10 minutes. Should impress the Court.

So, let's start with item H1, previous violence. Looks to me as though he is either a 0 or 1 on this. It may be a 1 as there are two or three minor incidents of aggression in his records. A couple of threats when he was 19 years old. He's now 26.

B Well, actually, no. He rates a 2 according to me.

A Why so? This stuff is pretty trivial and not very well substantiated.

B Well, you should note that the present alleged offences are to be included. That is, attempted murder, threatening death, false imprisonment and so on. That's what it says on page 29 .

A [Looks up page] You're right. It's a 2. [Marks it down]

Item H2, young age at first violent offence. These couple of documented threats of violence at age 19, call for a 2 then? [All nod]

Then there's this matter of relationship instability under H3. From what I can see from 
a. PCL-R, Psychopathy Checklist - Revised (Hare 1991); PCL:SV Psychopathy Checklist: Screening Version (Hart 1995). the record and from interview, Mr Lucas had a pretty strong relationship with his mother all through his life, right up until she died 2 years ago. Too bad he didn't do as well with his father. Also, Mr Lucas has had maybe half a dozen solid friendships with former school mates. So he merits a 0 on this item.

B No, I don't think so. This item hinges entirely on romantic relationships. There is no evidence at all that he has had any kind of sustained, intimate relationship with any woman, or man for that matter. He has never dated.

A If you say so. So I suppose that you all agree that this is a 2? [All nod]

We now deal with $\mathrm{H} 4$, employment problems. He's never worked at any job for more than a month. There has been a succession of shortrun labouring jobs. Mostly, he's been fired abruptly. It would seem that once he gets bored and once he gets paid, he fails to show up again. He's failed to complete numerous training programmes and has received a lot of social benefits. Surely, then, he scores a 2.

C Yes, no question about that. [All nod]

A Now we get to H5, substance use. So, as far as I can see, he's misused a fair number of substances, including alcohol. Still does. But really, when you look at it, the problem mainly is that he spends great chunks of his life wangling prescription drugs. He goes from doctor to doctor and often shows up at accident and emergency departments. So I think the actual substance use problem is pretty minor. Probably a 0 . But we could go for a 1 , I guess.

C Hang on a moment. The manual stresses that prescription drugs count as misuse (page 37).

A That may be, but it seems unfair to me. Let's give him a break and allot a score of 0 .

D I don't think we can bend the coding rules like that. Either we are administering this thing the way it is supposed to be applied, or we are doing something else altogether. No, I opt for a 2 based on my reading of the file.

A [Grudgingly] OK then, if you insist. [Marks down a 2]

He has never been hospitalised. That makes H6, major mental illness, straightforward. So I'd figure that would leave him with a 0 .

B True. He may never have been in a psychiatric hospital, but there is more than a suggestion in the records, which he does not disconfirm, that he has received periodic mental health services on an out-patient basis. In fact, he's attended various clinics, albeit not in sustained ways. A range of diagnoses are noted in the various reports on file. Mood disorder is mentioned quite often and paranoia crops up too. So, really, he meets criteria for a score of 1. [C and D nod. A marks down 1]

A H7 is called psychopathy. I've interviewed this guy and he is a psychopath if ever I saw one. He is straight out of Cleckley's The Mask of Sanity (Cleckley 1941). He knows it all. He boasts. He lies. He's got a big ego. He's manipulative. He's a 2 for sure.

D Now just a second, please. The manual on page 41 specifically warns against including this item when the person has not been formally evaluated according to the PCL-R or PCL:SV. ${ }^{\text {a }}$ If we haven't done this, we'd best omit the item, at least for now. We should, in fact, administer Hare's scheme as soon as possible.

A OK. Let's omit and we will pro-rate the historical scale score. Early maladjustment is next. Item H8.

C I read all the reports. They go way back. He has faced a very unfortunate past. Difficulties with his father extend a long way back. Victimised in school. Sent to various foster parents at different times. To me, it's a 2. [All agree. A marks it down]

A Now for H9. This should be easy and surely we are all agreed that he has got some features of a personality disorder. It is therefore a 2 .

C I dislike being a drag on the proceedings, but I don't think a 2 is right.

A Why so?

C Well, all we have here is some hints about a personality disorder. We've not examined this systematically and we've certainly not used tests. We haven't considered specific DSM-IV or ICD-10 definitions. If he does indeed have some traits, then a 1 might be justified. That's what it says on page 45 of the manual.

A OK then. [A marks it down]

So as far as H10, prior supervision failure, is concerned, he has never actually been in prison, or in a mental hospital for that matter. So it's hard to see if he can have escaped. It's got to be a 0 .

C True. He hasn't escaped, but he has in fact failed at least once to comply with an order to show up in court. It may seem a bit technical, but the manual would indicate that a 1 score would be about right. Also, he's never finished 
any of the programmes and courses which have been arranged for him.

A OK. It's a 1 then. But at the rate we are going, this guy is looking utterly beyond hope. So far, out of nine scored items we have a total score of 15 out of 18 . It seems a bit rough.

D Small point, but the idea, if I get it right, is neither to aim for a low score nor a high score. The goal is to be as impartial and disinterested as possible.

A Anyway, that's history behind us. On to current clinical factors, starting with $\mathrm{C} 1$, lack of insight. From my talks with him, I can't see that he possesses much in the way of selfknowledge. He seems quite unaware that he is out of step with most of society. He is very quick to blame others, very slow to accept any kind of responsibility for his own actions and reactions.

D Yes, we are going to have a challenge as we try to engage him in some kind of treatment plan. We're probably right to assign a 2 score but, really, we've now got to start figuring out the precise ways in which his insight is limited.

A Negative attitudes, C2. His criminal record and current alleged offence pretty much speak for themselves. A 2 then?

D No. We should be thinking about his present attitudes. On the basis of my meetings with him, he seems not to be particularly antisocial in outlook. He is fairly optimistic. I think a 1 would be right, at least for now. [B and C nod, A writes it down]

A Active symptoms of major mental illness, C3. What does everyone think?

C There are some definite indications of paranoid symptoms right now. I think, since the diagnostic picture is not yet fully clear, we should simply score him as a 1 provisionally.

B Alright. We'll start a proper diagnostic assessment.

A Impulsivity, C4. I'm not really clear about this. Some of you lot see him on a day-to-day basis. What do you think?

D He really does find it difficult to focus. His attention span is limited; when he wants something, he wants it now. He can't inhibit himself in any sustained way. At the very least he's at a 1 level. I would like to see him properly tested in this area. Why can't we score him provisionally at a 1 level and really look into this before our next meeting.
A I'm getting a bit nervous that we are not pinning all our scores down to a correct answer.

B I can't see why we worry about this. Part of the idea of the HCR-20, if I get it right, is to locate the areas which are in need of further examination. We can easily run through the process once again, once we have more information. I was recently reading something by this guy William Reid. He made the point that 'risk assessment is not a three-minute business'. ${ }^{\mathrm{b}}$ This is a pretty serious case. We need to be as sure of our opinion as we reasonably can be.

A So now let's turn to C5, unresponsive to treatment. He's a 2 for sure. He has almost no education, no interest in attending our substance misuse programme, no interest in our great social skills programme - the one our service manager raved about last month.

B Wait a minute, please. My impression is that he is now beginning to form a really constructive and supportive relationship with his primary nurse, Susie. She says he is beginning to engage with her and the programme.

A [Wearily] OK, OK, let's go for a 1. [All nod] OK, we are three-quarters of the way through now. Just five items to go. It's taking a lot longer than I'd hoped.

D Yeah, but I'm beginning to feel more confident and I like the idea that we're trying to reach a common understanding - one that should be helpful to our patient and also the court.

A R1, plans lack feasibility. There is no plan. 2, right?

B Well actually, very slowly over the past couple of weeks a bit of a plan is beginning to emerge. He's been with the Miracle Programme a couple of times in the past. Bob, our new social worker, has been to see the team over there and, I'm glad to say, they have some ideas that might work. Mr Lucas is grateful for this and is keenly interested. It will take another couple of weeks, but we may end up being able to propose to the court a workable plan. It's not a 2. Maybe a 1. [All nod]

A Let's try R2, exposure to destabilisers. I gather these are environmentally or situationally driven triggers. I even had to look this up in the manual. I don't think much of some of the characters in the group home he was in previously. He seems easily led by them. A 2 if ever there was one. 
C This is perhaps not right. He's here in the hospital now and will likely be here another couple of weeks at least. He is perfectly stable here. No one, or no particular set of circumstances, has so far set him off in here. At least, not in any serious kind of way. Notice that there is a box at the top of the ' $\mathrm{R}$ ' factors on the coding sheet. He could be rated either as 'in', meaning in the hospital, or 'out', meaning in the community. I would say that we rate him as 'in'. So he is at a 0.

A I suppose we could, if we wanted, rate him both 'in' and 'out'? If he were about to be released we could have a good look at the post-release circumstances and, depending on what they look like, we'd elevate a score to a 1 or perhaps even a 2 ?

D That's right.

A So now we're at item R3, lack of personal support. Ideas?

B I've been a little surprised of late. He's had a number of visits from friends, a few of whom I've met. They seem perfectly law abiding and they do express a strong interest in him and his future. One even offered him a job in a printing company. It's not the 2 he would automatically accrue. But, clearly, it's not a 0 since this apparent support is tenuous and of recent origin. Let's score it as a 1 as if he were 'out'. In here he is well supported - probably a 0. [All nod, A writes it down]

A At the rate we are going, our patient, despite these charges, is going to receive some sort of diploma for perfection in mental health.

B Well, I'm not quite saying that. But it does occur to me that whatever risk assessment scheme we elect to use should force us to consider all the options from all the angles. Properly used, this or any other similar scheme, should help us find solutions or opportunities, which would help the patient without jeopardising the safety of other people - including our staff members.

A OK, last but one item: R4, non-compliance with remediation attempts. He's never adhered to anything in the past. Surely he's an automatic 2 .

C It's true the history is not reassuring. But we mustn't forget that item $\mathrm{H} 10$ has to do with adherence in the past. We scored him a 2 on that. What we are attempting to do here is look towards the future. Certainly, he is talking seriously about getting some education and getting a job. Now it's true that a lot of this may have to do with trying to impress the court with the idea that he has reached some sort of epiphany, but there is, I think, some genuineness about this. Certainly, he's doing better and better in observing the rules of the unit. And he's started to attend the educational upgrading programme, even though he may not be here long enough to complete it. He has not, since admission, rejected his psychotropic medication. In here, he is a 0 . Were he to be on the outside right now he would likely be a 2 . So can we settle for a 1, at least for now? [All nod, A writes it down]

A Last item, R5, stress. Ideas?

B Well, actually, there are a whole lot of things which cause him stress which we haven't yet considered. One is his physical appearance. He's very worried about persistent acne. Another has to do with his debt load. He can't seem to get on top of his money. This bothers him no end. Another thing which hasn't yet been discussed is an emerging diabetic condition. He is taking medication, but now worries constantly about being hypoglycaemic. Then there's the issue of possible misuse of prescription drugs, which we've talked about. Then, of course, there's the issue of his father (who, by the way, has visited on a few occasions). There will be a great deal of difficulty in coping with his dad. But both of them seem to be trying in a guarded way. So in here, right now, he is coping very well. At a 0 level. But if we were to look at the immediate future out of here, we'd be entertaining a 1 or more likely a 2 .

A OK, so we are more or less done. According to my additions, he scores $25 / 38$ (or 31 if he were to be coded as 'out'), which I suppose means moderate risk. There doesn't seem to be any norms at the back of the manual, but common sense would suggest this - he is best classified as moderate risk.

B I can't agree. The manual is quite explicit in pointing out that, although there may be some general correspondence between the total score out of 40 and assigned overall risk level - the higher the score, the more likely he'll be found as 'high risk' - there will be some exceptions. This is discussed on page 22. No, on the assumption that he would be discharged to the community in the near future (on bail or whatever), it looks to me that he is actually high risk. He continues to express strong intent to kill his father. More specifically, his father will be at high risk of 
being attacked again until Mr Lucas's current paranoid symptoms abate. I'm glad to say he is now taking medication. A return home is not recommended in the near future. He represents a high risk to the father at present. And his father needs to be made fully aware of this.

A I am struggling to see the value in using this manual if we are going to ignore scores.

C It seems to me that we now have a better shared understanding of the relevant risk factors in this case. I skimmed a recent Department of Health document ${ }^{\mathrm{c}}$ which states that these types of structured risk assessment tools should be used to assist and not totally replace time-honoured conventional approaches to risk assessment. In many ways it might be better not to refer to the numbers at all. Stepping back, we're going to have to help him use the cards he already possesses. He is not without some strengths. With what we now know, we can begin to figure out a plan for discharge to the community, one that's as safe as we can manage. We also need to construct a plan to deal with any future crisis.

B [Brightly] I think the speaker at the workshop also said that it can be a good idea to go through these items again from time to time to check the integrity of our risk management plans. I'd be really interested to see if our 'C1 lacks insight' rating changes following his use of medication and with the increased individual help we're now providing.

A [Looking at watch] Now that would be very interesting. I'm afraid I need to get going. Well, I guess we should probably talk about using the HCR-20 routinely in our cases. What say I put it on the agenda for our next clinical governance meeting? [All nod violently].

\section{Epilogue}

There followed the novel but edifying sight of this team of professionals leaving a meeting with banter and some purpose. The team gradually introduced the HCR-20 into practice with adjustments to make it fit their local circumstances. Paperwork was cut down and procedures were amended to allow proper and thoughtful use of the scheme. Over the months, each practitioner became cognisant of their colleagues' individual contributions to the team effort. Naturally, professional differences, splits and other disagreements still occurred, but with time, the team found a way to maintain cohesion and make more effective decisions to keep patients such as Mr Lucas safe from harm.

\section{Conclusions}

Structured professional judgement approaches to risk assessment do not seek to dampen the differing values and experiences held by practitioners within mental health teams. Rather, the HCR-20 and related structured professional judgement schemes can be thought of as an organisational format that accommodates a plethora of cross-disciplinary concepts while providing a common professional language to foster consistent and transparent clinical practice. The scientific appraisal of risk can never be value-free, nor should it ignore the actual realities of clinical work. We have employed a whimsical device (see Spitzer 1981) to highlight the need for psychiatrists working in mental health to think very carefully about their own values as they undertake diagnostic assessments.

There is some evidence that multidisciplinary clinical judgement can achieve predictive accuracy substantially in excess of chance levels (Fuller 1999). We believe that consensus decision-making and related risk management planning are further enhanced by organising assessments through the use of structured professional judgement schemes such as the HCR-20. The use of empirical evidence to support clinical practice does not imply that the implementation of structured professional judgement will be any easier than when using alternative unstructured clinical approaches to clinical risk assessment. Indeed, we believe that there can be profound challenges in implementing structured professional judgement schemes such as the HCR20 , even if the device is used by a knowledgeable, enthusiastic and effective clinical team.

We suggest that the introduction of structured professional judgement approaches to a new clinical setting requires a detailed implementation plan, which includes a thorough assessment of the administrative, financial, human resource and policy requirements of adopting new methods in this field of practice. Training should be thorough and tailored to the requirements of the clinical team. Our 'play' highlights how easy it can be for individual practitioners, and even clinical teams, to drift from the explicit key principles laid out in structured professional judgement schemes. A framework of reflective practice, monitoring and supervision is therefore a key element of any implementation plan.

\section{References}

Cleckley H (1941) The Mask of Sanity. C.V. Mosby.

Department of Health (2007) Best Practice in Managing Risk: Principles and Evidence for Best Practice in the Assessment and Management of Risk to Self and Others in Mental Health Services. Department of Health.

\section{MCQ answers \\ $1 d \quad 2 d \quad 3 c \quad 4 b \quad 5 b$}

c. Department of Health (2007). 
Douglas K, Reeves K (2010) Historical-Clinical-Risk Management-20 (HCR-20) violence risk assessment scheme. In Handbook of Violence Risk Assessment (eds R Otto, KS Douglas): 147-85. Routledge.

Fuller F, Cowan J (1999) Risk assessment in a multidisciplinary forensic setting. Journal of Forensic Psychiatry 10: 276-89.

Hare RD (1991) Manual for the Hare Psychopathy Checklist - Revised. Multi-Health Systems.

Hart S, Cox D, Hare R (1995) Hare Psychopathy Checklist: Screening Version. Multi-Health Systems.

Khiroya R, Weaver T, Maden T (2009) Use and perceived utility of structured violence risk assessment in English medium secure forensic units. Psychiatric Bulletin 33: 129-31.

Maden A (2007) Treating Violence: A Guide to Risk Management in Mental Health. Oxford University Press.
Pfohl SJ (1979) Predicting Dangerousness: The Social Construction of Psychiatric Reality. Lexington Books.

Reid WH (2003) Risk assessment, prediction, and forseeability. Journal of Psychiatric Practice 7: 82-6.

Spitzer R (1981) The diagnostic status of homosexuality in DSM-III: a reformulation of the issues. American Journal of Psychiatry 138: 210-5.

Webster CD, Douglas KS, Eaves D, et al (1997) HCR-20. Assessing Risk for Violence, Version 2. Mental Health, Law and Policy Institute, Simon Fraser University.

Webster CD, Müller-Isberner R, Fransson G (2002) Violence risk assessments: using structured clinical guidelines professionally. International Journal of Forensic Mental Health 1: 185-93.

Webster CD, Hucker SJ (2007) Violence Risk: Assessment and Management. Wiley-Blackwell.

\section{MCOs}

Select the single best option for each question stem

\section{Best Practice in Managing Risk} (Department of Health 2007):

a states that structured professional judgement should replace clinical decision-making

$\mathrm{b}$ argues that clinicians must be wary of taking carers' opinions into account

c applies exclusively to forensic mental health services

d supports multidisciplinary involvement when devising risk management plans

e states that the HCR-20 is the best available risk assessment tool.

\section{The HCR-20:}

a is best thought of as a checklist

b can only be completed by a consultant psychiatrist

c is a psychological test

$\mathrm{d}$ can be conceptualised as a clinical guideline

e primarily concerns itself with the prediction rather than prevention of violence against other persons.

\section{When coding the HCR-20:}

a it is acceptable to stop referring to the manual once fully trained

b case-specific factors not included in the list of 20 items are not considered to be relevant

c it is permissible to code each item as 'yes' 'maybe' or 'no' instead of ' 2 ', ' 1 ' and ' 0 ' respectively

$d$ it is best to decide in advance the service user's level of risk and allot item scores accordingly

e someone with a low total score cannot be judged to present with a high risk of violence to others.

4 To be proficient in the use of the HCR-20, it is necessary:

a to attend a 2-day workshop and achieve a passing grade

b to continue referring to the manual with each case in hand

c to pay limited attention to the relevant scientific and professional literature

$d$ to ignore any information that does not directly refer to the 20 stated risk factors

e to have statistical expertise.
5 The HCR-20 can aid risk management by:

a specifically isolating critical factors related to emerging suicide risk

b promoting interdisciplinary discussion and planning

c providing extremely accurate predictions of violence potential

$\mathrm{d}$ removing any reliance on clinical acumen

e creating a cut-off score above which a violence outcome is almost certain. 